\title{
Automobile Tire Assessment: A Multi-Criteria Approach
}

\author{
Ateekh-Ur-Rehman \\ Industrial Engineering Department, College of \\ Engineering, King Saud University, Riyadh, KSA \\ arehman@ksu.edu.sa
}

\author{
Mohammed Alkahtani \\ Industrial Engineering Department, College of \\ Engineering, King Saud University, Riyadh, KSA \\ moalkahtani@ksu.edu.sa
}

\begin{abstract}
In response to the present dynamic market, automobile manufacturing industries are constantly evaluating and improving their manufacturing strategies to stay competitive. It is also evident that they evaluate those strategies considering multiple criteria. In one such case, an automobile project manager has to ensure that the selected tire (among the available alternatives) complies with the prospective automobile's performance. This paper presents an approach for the assessment of alternative automobile tires taking into account multiple criteria, such as tire sustainability, tire road performance, environmental issues, tire purchase cost and tire road grip. The presented approach is quite helpful to any decision maker who is interested not only in ranking alternatives but also in establishing the superiority of an alternative over others. The approach also helps to specify the position of each alternative with respect to ideal solution. A case illustration is used to demonstrate an application of the approach.
\end{abstract}

\section{Keywords-automobile tire; multi-criteria; decision making}

\section{INTRODUCTION}

In the tire market, there is a wide variety of tires for light \& heavy automobiles. Therefore, the justification of tire choice is an important and a crucial issue. Thus, in response to the present dynamic market and green ecofriendly need, automobile manufacturing industries are constantly evaluating and improving their vendor selection strategies to stay competitive. Nowadays, the automobile sector is receiving much attention from the research community. As tires plays an important role in an automobile's performance, an automobile manufacturer has to select tires that are correctly sized and rated for its automobile to fulfill a fundamental set of criteria, such as load-carrying capacity, cushioning, dampening, braking torque, cornering force, dimensional stability, steering response, rolling resistance, and expected life span [1-3]. Researchers also highlighted that elongation and tensile strength of the tire are important as quality control criteria in evaluating automobile road performance $[4,5]$.

From the open source database, it is clear that there is an enormous increase in major road accidents. A significant contributing factor to these accidents is tire failure. A field investigation of eight different brands of tires to understand the reasons for tire failure was reported in [4]. For example, catastrophic separation and tire blowouts are common events directed to serious road accidents [6]. Tire blowouts are extremely a safety issue concern. Close to $13 \%$ of road accidents reported are attributed to tire failure [7]. Hence, one of the issues faced by the automobile research and development department is to test the alternative tires on multiple measures. The present paper attempts to present an approach to assess alternative automobile tires taking into account multiple criteria, such as tire sustainability, tire road performance, environmental issues, tire purchase cost and tire road grip. A case study is presented to show an application of the approach.

\section{MULTI-CRITERIA DECISION MAKING: A REVIEW}

Multi-criteria decision-making approaches are widely used in service and manufacturing industries. Any decision-making approach concerned with the task of ranking a set of finite alternatives. Researchers [8-9] have reviewed common multicriteria decision making approaches and examined the advantages and disadvantages and also explained the relative strengths and weaknesses. Some of the multi-criteria decisionmaking approaches use additive formulas to classify the alternatives on hand. The summary of the most commonly used multi-criteria decision-making methods presented below:

- Analytic Hierarchy Process (AHP): A multi-criteria decision making approach introduced in [10]. The approach needs the decision tree with the goal at the top-level, criteria and sub-criteria in middle levels, and the alternatives at the bottom. In AHP, the experts and decision makers do pairwise comparison and select the best alternative according to the highest rank between alternatives. The drawback of the approach is that its unidirectional relationship characteristic cannot handle the complexity of many problems.

- Analytic Network Process (ANP): The ANP method is a general form of the AHP, ANP introduced in [9]. ANP partly overcomes the drawback of AHP and deals with the problem as a network of complex relationships between alternatives and criteria where all elements are connected [11].

- Preference ranking organization method for enrichment evaluation (PROMETHEE): This method uses the positive and negative outranking flows to rank the alternatives. These outranking flows do not usually induce the same rankings. Subsequently, the approach considers the net outranking flow to do a pair-wise comparison of 
alternatives to rank them with respect to multiple criteria [12].

- The elimination and choice translating reality (ELECTRE): The ELECTRE approach focused on the dominance relations between alternatives. It is based on outranking relationships, and uses thresholds of indifference \& preference to do pair-wise comparison between alternatives [13]. As the approach incorporates the fuzzy nature of decision-making, decision makers prefer the ELECTRE approach over the other approaches.

- The technique for order preference by similarity to ideal solutions (TOPSIS): This approach is based on the concept that the selected alternative should have the shortest distance from the positive ideal solution and the farthest distance from the negative ideal solution. The approach demarcates the positive ideal and negative ideal solutions. In this approach, the Euclidean distance approach is used to check the relative closeness of the alternatives to the ideal solution [14-15].

In general, multi-criteria decision-making approaches have the following basic steps [15]: (a) Formulate of the decision tree using alternatives, criteria and sub-criteria (b) Determine the relative importance of the criteria and the impacts of the alternatives on these criteria. (c) Process the numerical values to find a ranking of each alternative. Apply value judgment on acceptable tradeoffs and evaluation, and (d) calculate final ranking and make decision.

Researchers and practitioners have adopted multi-criteria decision analysis in some industrial applications, such as in manufacturing technology investment decisions [16], for evaluation of energy plans [6] and for manufacturing nonfinancial justification [17]. In particular, automobile researchers adopted multi-criteria decision approach to select suitable tires for two-wheel drive tractors operating in sandy clay loam soils [18]. An intelligent tire model derived that can show the relationships between driving conditions and tire strain [19]. Similarly, a qualitative formula developed to estimate the tire wear [20].

\section{COMPARATIVE ASSESSMENT : AN APPROACH}

An integrated multi criteria approach for an automobile tire assessment presented here in this section. The approach evaluates the decision hierarchy and derives weights for each criteria and sub-criteria using AHP [9-10] (refer steps 1 to 3). These weights are further used to do comparative assessment using TOPSIS approach [14-15] (refer steps 4 to 9). The details about each step and calculations involved are presented here below.

\section{Step 1: Develop the decision hierarchy}

The approach needs a decision hierarchy, with the goal at the top-level, the criteria and the sub-criteria (attributes) in middle levels, and the alternatives at the bottom. Figure 1 illustrates the decision hierarchy.

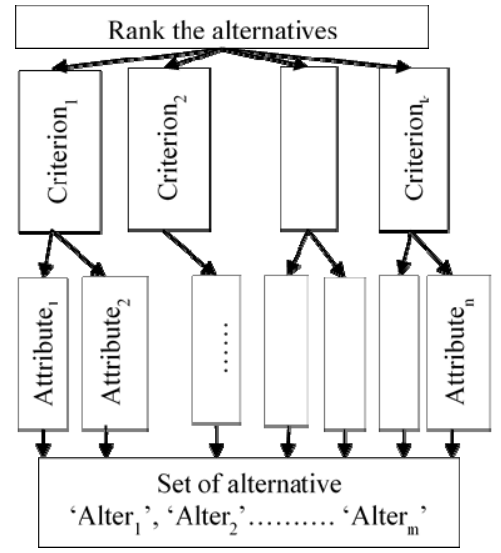

Fig. 1. The decision hierarchy

\section{Step 2: Do pairwise comparisons of criteria and attributes}

In is recommends that these pairwise comparisons be carried out using verbal responses and or non-verbal responses [10]. For example, the decision maker asked to answer whether Criterion $_{1}$ and Criterion $_{2}$ are of equal importance or whether one is more important than the other. If he/she indicates that Criterion $_{1}$ is more important, later he/she has to specify is Criterion $_{1}$ : weakly more important, strongly more important, very strongly more important or extremely more important?

Resulted set of comparisons expressed in the form of criteria comparative matrix (CCM) as given below.

$$
\mathrm{CCM}=\left[\begin{array}{cccccccc}
\text { Criteria } \downarrow \rightarrow & \mathrm{C}_{1} & \mathrm{C}_{2} & . & \mathrm{C}_{\mathrm{k}} & . & . & \mathrm{C}_{1} \\
\mathrm{C}_{1} & 1 & \mathrm{x} & . & . & . & . & . \\
\mathrm{C}_{2} & 1 / \mathrm{x} & 1 & . & . & . & . & . \\
. & . & . & . & . & . & . & . \\
\mathrm{C}_{\mathrm{k}} & . & . & . & 1 & . & . & . \\
. & . & . & . & . & . & . & . \\
. & . & . & . & . & . & 1 & 1 / \mathrm{y} \\
\mathrm{C}_{1} & . & . & . & . & . & \mathrm{y} & 1
\end{array}\right]
$$

In the above matrix, the criterion $\mathrm{C}_{1}$ is $\mathrm{x}$ times more important than criterion $\mathrm{C}_{2}$. Similarly, do pairwise comparison for group of attributes for a given criterion. Resulted set of comparisons expressed in the form of attribute comparative matrix (ACM) as below.

$$
\mathrm{ACM}=\left[\begin{array}{ccccccc}
\text { Attrb } \downarrow \rightarrow & \mathrm{A}_{1} & \mathrm{~A}_{2} & \cdot & \mathrm{A}_{\mathrm{j}} & \cdot & \mathrm{A}_{\mathrm{n}} \\
\mathrm{A}_{1} & 1 & \mathrm{z} & \cdot & \cdot & \cdot & \cdot \\
\mathrm{A}_{2} & 1 / \mathrm{z} & 1 & \cdot & \cdot & \cdot & \cdot \\
\cdot & \cdot & \cdot & \cdot & \cdot & \cdot & \cdot \\
\mathrm{A}_{\mathrm{j}} & \cdot & \cdot & \cdot & 1 & \cdot & \cdot \\
\cdot & \cdot & \cdot & \cdot & \cdot & \cdot & \cdot \\
\mathrm{A}_{\mathrm{n}} & \cdot & \cdot & \cdot & \cdot & \cdot & 1
\end{array}\right]
$$

In the above matrix, the attribute $\mathrm{A}_{1}$ is $\mathrm{z}$ times more important than attribute $\mathrm{A}_{2}$. 
Step 3: Transform the pairwise comparisons of attributes into attributes weight:

After each comparison done, the obtained values converted by AHP process into a set of weights, which are then normalized. An approach based on eigenvalues is recommended [10]. Since this involves a relative complex mathematical procedure, software such as Super decision is used. These weights are subsequently used to get weighted normalized matrix. The normalized weights for attribute $\left(\mathrm{W}_{\mathrm{j}}\right)$ expressed as (3).

$$
\mathrm{W}_{\mathrm{j}}=\left[\begin{array}{llllll}
\mathrm{W}_{1} & \mathrm{~W}_{2} & . & \mathrm{W}_{\mathrm{n}-1} & \mathrm{~W}_{\mathrm{n}}
\end{array}\right] \text { for attributes }
$$

Step 4: Establish decision matrix and calculate normalized decision matrix:

Qualitative and quantitative data for given alternatives expressed as decision matrix (DM) as given below.

$$
\mathrm{DM}=\left[\begin{array}{cccccc}
\downarrow \rightarrow & \mathrm{A}_{1} & \cdot & \mathrm{A}_{\mathrm{j}} & \cdot & \mathrm{A}_{\mathrm{n}} \\
\text { Alter }_{1} & \mathrm{X}_{11} & \cdot & \cdot & \cdot & \mathrm{X}_{\mathrm{ln}} \\
\cdot & \cdot & \cdot & \cdot & \cdot & \cdot \\
\text { Alter }_{i} & \mathrm{X}_{\mathrm{i} 1} & \cdot & \mathrm{X}_{\mathrm{ij}} & \cdot & \mathrm{X}_{\mathrm{in}} \\
\cdot & \cdot & \cdot & \cdot & \cdot & \cdot \\
\text { Alter }_{\mathrm{m}} & \mathrm{X}_{\mathrm{m} 1} & \cdot & \cdot & \cdot & \mathrm{X}_{\mathrm{mn}}
\end{array}\right]
$$

In the above matrix (4) 1 to $\mathrm{m}$ are alternatives and 1 to $\mathrm{n}$ are the attributes. $\mathrm{X}_{11}$ represents data entry for an alternative (Alter $\left.{ }_{1}\right)$ with respect to an attribute $\left(A_{1}\right)$. This information is further treated as a decision matrix and transformed into the normalized decision matrix (NDM). The NDM represents relative performance of existing alternatives and represented in matrix form as.

$$
\mathrm{NDM}=\left[\begin{array}{cccccc}
\mathrm{i} \downarrow j \rightarrow & \mathrm{A}_{1} & \cdot & \mathrm{A}_{\mathrm{j}} & \cdot & \mathrm{A}_{\mathrm{n}} \\
\text { Alter }_{1} & \mathrm{R}_{11} & \cdot & \cdot & \cdot & \mathrm{R}_{\mathrm{ln}} \\
\cdot & \cdot & \cdot & \cdot & \cdot & \cdot \\
\text { Alter }_{\mathrm{i}} & \mathrm{R}_{\mathrm{il}} \cdot & \cdot & \mathrm{R}_{\mathrm{ij}} & \cdot & \mathrm{R}_{\mathrm{in}} \\
\cdot & \cdot & \cdot & \cdot & \cdot & \cdot \\
\text { Alter }_{\mathrm{m}} & \mathrm{R}_{\mathrm{m} 1} & \cdot & \cdot & \cdot & \mathrm{R}_{\mathrm{mn}}
\end{array}\right]
$$

The NDM data obtained using DM and (6).

$$
\mathrm{R}_{\mathrm{ij}}=\frac{\mathrm{x}_{\mathrm{ij}}}{\sqrt{\sum_{i} \mathrm{X}_{\mathrm{ij}}^{2}}}
$$

In (6), $X_{i j}$ is measured value of alternative $i$ with respect to attribute $j$ and $R_{i j}$ is the normalized score for alternative $i$ w.r.t attribute $\mathrm{j}$.

\section{Step 5: Construct the weighted normalized decision matrix:}

This step uses of set of criteria and attributes weight obtained at step 3. Thus the normalized decision matrix value $\mathrm{R}_{\mathrm{ij}}$ is converted into the weighted normalized. The WDM data is obtained using (8).
Step 6: Establish the ideal and negative ideal solution:

Let $\mathrm{J}_{\max }$ be the set of attributes (where preference is 'maximum value') and $J_{\min }$ be the set of negative attributes (where preference is 'minimum value'). The positive ideal solution set expressed as (9).

$$
\begin{aligned}
& \mathrm{WDM}=\left[\begin{array}{cccccc}
\mathrm{i} \downarrow j \rightarrow & \mathrm{A}_{1} & \cdot & \mathrm{A}_{\mathrm{j}} & \cdot & \mathrm{A}_{\mathrm{n}} \\
\text { Alter }_{1} & \mathrm{~V}_{11} & \cdot & \cdot & \cdot & \mathrm{V}_{\text {ln }} \\
\cdot & \cdot & \cdot & \cdot & \cdot & \cdot \\
\text { Alter }_{\mathrm{i}} & \mathrm{V}_{\mathrm{il}} & \cdot & \mathrm{V}_{\mathrm{ij}} & \cdot & \mathrm{V}_{\mathrm{in}} \\
\cdot & \cdot & \cdot & \cdot & \cdot & \cdot \\
\text { Alter }_{\mathrm{m}} & \mathrm{V}_{\mathrm{m} 1} & \cdot & \cdot & \cdot & \mathrm{V}_{\mathrm{mn}}
\end{array}\right] \\
& \mathrm{V}_{\mathrm{ij}}=\mathrm{W}_{\mathrm{j}} \times \mathrm{R}_{\mathrm{ij}} \\
& V^{*}=\left\{V_{1}^{*}, V_{2}^{*}, \ldots V_{j}^{*} \ldots . . V_{n}^{*}\right\}
\end{aligned}
$$

In (9),

$$
\mathrm{V}_{\mathrm{j}}^{*}=\left\{\max \mathrm{V}_{\mathrm{ij}} \text { if }\left(\mathrm{j} \in \mathrm{J}_{\max }\right) \text { or } \min \mathrm{V}_{\mathrm{ij}} \text { if }\left(\mathrm{j} \in \mathrm{J}_{\min }\right)\right\}
$$

The negative ideal solution set expressed as below.

$$
\mathrm{V}^{\prime}=\left\{\mathrm{V}_{1}^{\prime}, \mathrm{V}_{2}^{\prime}, \ldots \mathrm{V}_{\mathrm{j}}^{\prime} \ldots \ldots \mathrm{V}_{\mathrm{n}}^{\prime}\right\}
$$

Where $\mathrm{V}_{\mathrm{j}}^{\prime}=\left\{\min \mathrm{V}_{\mathrm{ij}}\right.$ if $\left(\mathrm{j} \in \mathrm{J}_{\max }\right)$ or $\max \mathrm{V}_{\mathrm{ij}}$ if $\left.\left(\mathrm{j} \in \mathrm{J}_{\min }\right)\right\}$

Step 7: Establish the separation measures for each alternative:

The separation measure for an alternative from the ideal alternative $\mathrm{S}_{\mathrm{i}}^{*}$ is established using (11).

$$
\mathrm{S}_{\mathrm{i}}^{*}=\left[\sum_{\mathrm{j}}\left(\mathrm{V}_{\mathrm{j}}^{*}-\mathrm{V}_{\mathrm{ij}}\right)^{2}\right]^{\frac{1}{2}}
$$

Similarly, the separation measure for an alternative from the worst alternative $\mathrm{S}_{\mathrm{i}}^{\prime}$ is established using (12).

$$
\mathrm{S}_{\mathrm{i}}^{\prime}=\left[\sum_{\mathrm{j}}\left(\mathrm{V}_{\mathrm{j}}^{\prime}-\mathrm{V}_{\mathrm{ij}}\right)^{2}\right]^{1 / 2}
$$

In above (11) and (12), the number of alternatives varies from 1 to $\mathrm{m}, \mathrm{V}_{\mathrm{ij}}$ is weighted normalized data for an alternative $\mathrm{i}$ with respect to an attribute $\mathrm{j}$.

Step 8: Establish the relative closeness of an alternative with respect to the ideal solution:

The closeness measure $\mathrm{C}^{*}$ for an alternative with respect to the ideal alternative established using (13).

$$
\mathrm{C}_{\mathrm{i}}^{*}=\frac{\mathrm{S}_{\mathrm{i}}^{\prime}}{\left(\mathrm{S}_{\mathrm{i}}^{*}+\mathrm{S}_{\mathrm{i}}^{\prime}\right)}
$$

Where, $\mathrm{S}_{\mathrm{i}}^{*}$ is the separation measure for an alternative from the ideal alternative, and $S_{i}^{\prime}$ is the separation measure for an alternative from the worst alternative and while, $\mathrm{C}_{\mathrm{i}}^{*}$ is the closeness measure. Note $C^{*}$ i satisfies $0<C^{*}{ }_{i}<1$. The obtained values of $\mathrm{V}_{\mathrm{ij}}, \mathrm{V}_{\mathrm{j}}^{*}, \mathrm{~V}_{\mathrm{j}}, \mathrm{S}_{\mathrm{i}}^{*}, \mathrm{~S}_{\mathrm{i}}^{\prime}$ and $\mathrm{C}_{\mathrm{i}}^{*}$ in matrix form as closeness matrix (CM) (refer to (14)).

Step 9: Select the best alternative:

Finally the alternatives ranked in descending order based on closeness value $\mathrm{C}_{\mathrm{i}}^{*}$. 


$$
\mathrm{CM}=\left[\begin{array}{cccccccc}
\mathrm{i} \downarrow j \rightarrow & \mathrm{A}_{1} & \mathrm{~A}_{2} & \cdot & \mathrm{A}_{\mathrm{n}} & \mathrm{S}_{\mathrm{i}}^{*} & \mathrm{~S}_{\mathrm{i}}^{\prime} & \mathrm{C}_{\mathrm{i}}^{*} \\
\text { Alter }_{1} & \mathrm{~V}_{11} & \mathrm{~V}_{12} & \cdot & \mathrm{V}_{1 \mathrm{n}} & \mathrm{S}_{1}^{*} & \mathrm{~S}_{1}^{\prime} & \mathrm{C}_{1}^{*} \\
\text { Alter }_{2} & \mathrm{~V}_{21} & \mathrm{~V}_{22} & \cdot & \mathrm{V}_{2 \mathrm{n}} & \mathrm{S}_{2}^{*} & \mathrm{~S}_{2}^{\prime} & \mathrm{C}_{2}^{*} \\
\cdot & \cdot & \cdot & \cdot & \cdot & \cdot & \cdot & \cdot \\
\text { Alter }_{\mathrm{m}} & \mathrm{V}_{\mathrm{m} 1} & \mathrm{~V}_{\mathrm{m} 2} & \cdot & \mathrm{V}_{\mathrm{mn}} & \mathrm{S}_{\mathrm{m}}^{*} & \mathrm{~S}_{\mathrm{m}}^{\prime} & \mathrm{C}_{\mathrm{m}}^{*} \\
\mathrm{~V}_{\mathrm{j}}^{*} & \cdot & \cdot & \cdot & \cdot & \cdot & - & - \\
\mathrm{V}_{\mathrm{j}}^{\prime} & \cdot & \cdot & \cdot & \cdot & \cdot & - & -
\end{array}\right]
$$

\section{APPLICATION OF THE APPROACH}

At the start the general goal was stated as 'to rank the available alternative tires'. There were five criteria considered such as tire sustainability (TSU), tire performance (TP), tire grip (TG), tire environmental hazard (TEH) and tire cost (TC). As shown in Figure 2, these criteria were further fragmented down into attributes at next level. For example, criterion tire sustainability, the attributes tire carrying load capacity (TLC), tire cushioning, and tire long lasting (TLL) quantified. Similarly, for criterion tire performance, the attributes tire thread depth (TTD) and tire maximum speed (TS) measured. Whereas, for criterion tire environmental hazard, the attributes tire noise pollution (TNP) and tire rolling resistance (TRR) measured. And, for criterion tire grip, the attributes such as tire dry grip (TDG) and tire wet grip (TWG) scores obtained. Finally, the alternatives added in the lower level to the hierarchy.

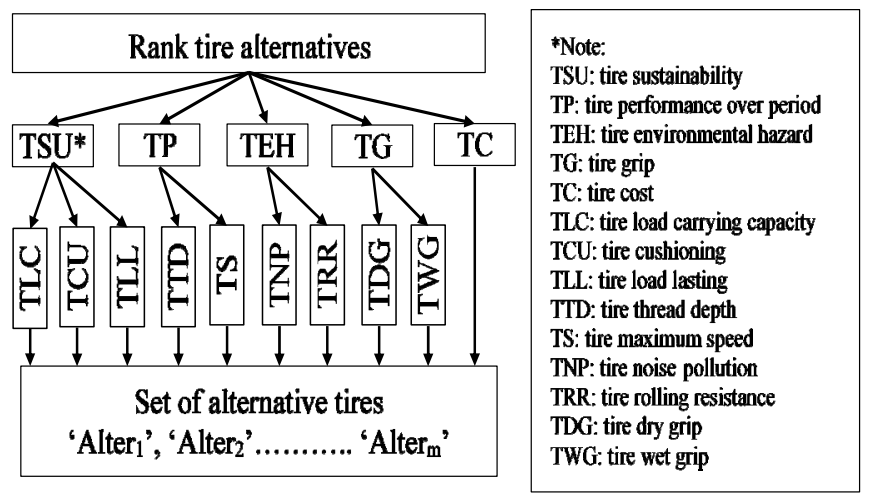

Fig. 2. Automobile tire decision hierarchy

Pairwise comparisons carried out using quantitative and qualitative responses. For example, in order to assess whether TSU and TP criteria had equal importance or whether one was more important than the other. If the professional indicated that TP was more important, then he was later asked if the TP was weakly more important, strongly more important, very strongly more important, or extremely more important. Likewise, pairwise comparisons were carried out.

The obtained pairwise comparative data expressed (refer to (1)) as in the form of criteria comparative matrix (CCM). In the following CCM matrix, the TSU quantified 3 times more important than criterion TP. Subsequently, decision makers asked to do pairwise comparison of attributes for each criterion.
The outcome of experts' opinion expressed (refer to (2)) as ACM matrix.

$\mathrm{CCM}=\left[\begin{array}{cccccc}\text { Criteria } \downarrow \rightarrow & \text { TSU } & \text { TP } & \text { TEH } & \text { TG } & \text { TC } \\ \text { TSU* } & 1 & 3 & 4 & 2 & 2 \\ \text { TP } & 0.33 & 1 & 2 & 0.5 & 0.33 \\ \text { TEH } & 0.25 & 0.5 & 1 & 0.5 & 0.33 \\ \text { TG } & 0.5 & 2 & 2 & 1 & 2 \\ \text { TC } & 0.5 & 3 & 3 & 0.5 & 1\end{array}\right]$
$\left[\begin{array}{cccc}\text { for TSU* } & \text { TLC } & \text { TCU } & \text { TLL } \\ \text { TLC } & 1 & 3 & 0.5 \\ \text { TCU } & 0.33 & 1 & 0.33 \\ \text { TLL } & 2 & 3 & 1\end{array}\right]\left[\begin{array}{cccc}\text { for TEH } & \text { TNP } & \text { TRR } \\ \text { TNP } & 1 & 0.5 \\ \text { TRR } & 2 & 1\end{array}\right]$

$\mathrm{ACM}=$

$\left[\begin{array}{ccc}\text { for TG } & \text { TDG } & \text { TWG } \\ \text { TDG } & 1 & 3 \\ \text { TWG } & 0.33 & 1\end{array}\right]\left[\begin{array}{ccc}\text { for TP } & \text { TTD } & \text { TS } \\ \text { TTD } & 1 & 2 \\ \text { TS } & 0.5 & 1\end{array}\right]$

*Refer to Figure 2

The cell values in the above set of matrices represent pairwise comparison of attributes for the given criterion. As presented, decision makers stated that for the given criterion TSU, the attribute TLC was three-time more important than TCU, and while TLL was three times more important than TCU and two times more important than TLC. After pairwise comparison of attribute, the obtained scores converted into normalized weights (refer to (3)). The obtained normalized weights were as:

$\mathrm{W}_{\mathrm{j}}=\left[\begin{array}{cccccccccc}\text { TLC } & \text { TCU } & \text { TLL } & \text { TNP } & \text { TRR } & \text { TTD } & \text { TS } & \text { TDG } & \text { TWG } & \text { TC } \\ 0.0807 & 0.0337 & 0.1228 & 0.0809 & 0.1619 & 0.1619 & 0.0809 & 0.1823 & 0.0607 & 0.0288\end{array}\right]$

Table I presents the list of the alternative tires. It highlights the performance of alternative tires aligned with multiple criteria and their attributes. As presented in Table I, qualitative and quantitative data for given alternatives expressed (refer to (4)) as decision matrix (DM). It is clear that each attributes have different dimensions to measure. There is a need to transform various attribute dimensions into non-dimensional attributes, and to do neutral comparisons across criteria and attributes. The obtained outcome is presented in Table II. Taking into account each of these normalize decision matrix and attribute weights for each alternative, weighted normalized decision matrix derived using (9), the derived outcome is as presented in Table III. Subsequently, attributes categorized into two sets as $\mathrm{Vj}^{*}$ and $\mathrm{V}^{\prime} \mathrm{j}$, the set of maximization attributes and minimization attributes.

In Table III, $\mathrm{Wj}$ is weight for attribute $\mathrm{j}, \mathrm{Vj}^{*}$ is ideal solution for attribute $\mathrm{j}$, and $\mathrm{Vj}$ is negative ideal solution for attribute $\mathrm{j}$. Subsequently, to perform the sensitivity analysis, in the presented approach different set of weights used (Table IV). The separation measure for all alternative tires and their closeness value with respect to the best and worst solution obtained and corresponding closeness score $\mathrm{Ci}^{*}$ for each alternative presented in Table V. Subsequently, these alternative tires are ranked based on closeness score $\mathrm{Ci}^{*}$. In 
Table $\mathrm{V}, \mathrm{Si}^{*}$ is separation measure for given alternative $\mathrm{i}$ from ideal alternative, $\mathrm{Sj}$ is separation measure for given alternative $\mathrm{i}$ from negative ideal alternative and $\mathrm{Ci}^{*}$ is closeness measure for alternative $i$.

TABLE I. INPUT DATA FOR ASSESSMENT OF ALTERNATIVE TIRES

\begin{tabular}{|c|c|c|c|c|c|c|c|c|c|c|c|}
\hline \multirow{4}{*}{$\begin{array}{c}\text { Tire } \\
\text { Codes }\end{array}$} & \multicolumn{3}{|c|}{ TSU* } & \multicolumn{3}{|c|}{ TP } & \multicolumn{2}{|c|}{ TEH } & TC & \multicolumn{2}{|c|}{ TG } \\
\hline & $T L C$ & $\mid T C U$ & $T L L$ & TTD & $T S$ & & \begin{tabular}{l|l}
$T N P$ & 1 \\
\end{tabular} & $\begin{array}{l}R R \\
\end{array}$ & $T C$ & $T D G$ & $T W G$ \\
\hline & $\max \#$ & $\max$ & $\max$ & $\max$ & \multicolumn{2}{|c|}{$\max$} & $\min$ & $\min$ & $\min$ & $\max$ & $\max$ \\
\hline & $\mathrm{kg}$ & \multicolumn{2}{|c|}{ scale months } & $\begin{array}{ll}\mathrm{s} & \mathrm{mm}\end{array}$ & \multicolumn{2}{|c|}{$\mathrm{Km} / \mathrm{hr}$} & ratio & ratio & $\$$ & $\%$ & $\%$ \\
\hline T01 & 1060 & 3 & 12 & 8.2 & \multicolumn{2}{|c|}{180} & 5.5 & 18 & 5 & 91.8 & 54 \\
\hline T02 & 1090 & 5 & 30 & 9 & \multicolumn{2}{|c|}{200} & 2 & 12 & 3 & 95.2 & 58 \\
\hline T03 & 1120 & 4 & 24 & 9 & \multicolumn{2}{|c|}{200} & 4 & 14 & 5 & 94.5 & 57.5 \\
\hline T04 & 1060 & 2 & 18 & 8.4 & \multicolumn{2}{|c|}{190} & 6 & 16 & 5 & 92 & 53 \\
\hline T05 & 1090 & 3 & 20 & 8.6 & \multicolumn{2}{|c|}{200} & 5.5 & 18 & 3 & 91.5 & 55 \\
\hline T06 & 1090 & 4 & 20 & 8.6 & \multicolumn{2}{|c|}{210} & 3 & 14 & 2 & 92.7 & 58.8 \\
\hline T07 & 1000 & 4 & 24 & 8.6 & \multicolumn{2}{|c|}{200} & 3 & 13 & 2 & 93 & 56.5 \\
\hline T08 & 1060 & 3 & 18 & 8.4 & \multicolumn{2}{|c|}{170} & 5 & 17 & 3 & 90 & 53.2 \\
\hline T09 & 1090 & 5 & 30 & 8.6 & \multicolumn{2}{|c|}{190} & 3.5 & 15 & 5 & 95.8 & 56 \\
\hline T10 & 1060 & 4 & 20 & 8.8 & \multicolumn{2}{|c|}{210} & 2.5 & 13 & 1 & 95 & 57 \\
\hline T11 & 925 & 3 & 18 & 8.4 & \multicolumn{2}{|c|}{210} & 6 & 18 & 4 & 89 & 53 \\
\hline T12 & 112 & 4 & 18 & 8.8 & 21 & & 4.5 & 12 & 3 & 93 & 55.7 \\
\hline T13 & 112 & 5 & 24 & 9 & 18 & & 3.5 & 16 & 2 & 94.5 & 56.7 \\
\hline TCU Sc & & Very goc & & Good & & Sat & isfactory & & erage & Below & average \\
\hline & & 5 & & 4 & & & 3 & & 2 & & \\
\hline TC Scor & & Above $\$ 5$ & & 400 to 5 & & $\$ 25$ & 50 to 400 & $0 \$ 15$ & to 250 & Belo & $\$ 150$ \\
\hline & & 5 & & 4 & & & 3 & & 2 & & \\
\hline
\end{tabular}

TABLE II. NORMALIZED SCORES FOR EACH ATTRIBUTE \& ALTERNATIVE

\begin{tabular}{|c|c|c|c|c|c|c|c|c|c|c|}
\hline Codes $\downarrow$ & TLC & TCU & TLL & TTD & TS & TNP & TRR & TC & TDG & TWG \\
\hline T01 & 0.27 & 0.21 & 0.15 & 0.26 & 0.25 & 0.35 & 0.33 & 0.39 & 0.27 & 0.27 \\
\hline T02 & 0.28 & 0.36 & 0.38 & 0.29 & 0.28 & 0.13 & 0.22 & 0.23 & 0.28 & 0.29 \\
\hline T03 & 0.29 & 0.29 & 0.31 & 0.29 & 0.28 & 0.25 & 0.25 & 0.39 & 0.28 & 0.29 \\
\hline T04 & 0.27 & 0.14 & 0.23 & 0.27 & 0.27 & 0.38 & 0.29 & 0.39 & 0.27 & 0.26 \\
\hline T05 & 0.28 & 0.21 & 0.25 & 0.28 & 0.28 & 0.35 & 0.33 & 0.23 & 0.27 & 0.27 \\
\hline T06 & 0.28 & 0.29 & 0.25 & 0.28 & 0.30 & 0.19 & 0.25 & 0.16 & 0.28 & 0.29 \\
\hline T07 & 0.26 & 0.29 & 0.31 & 0.28 & 0.28 & 0.19 & 0.24 & 0.16 & 0.28 & 0.28 \\
\hline T08 & 0.27 & 0.21 & 0.23 & 0.27 & 0.24 & 0.32 & 0.31 & 0.23 & 0.27 & 0.26 \\
\hline T09 & 0.28 & 0.36 & 0.38 & 0.28 & 0.27 & 0.22 & 0.27 & 0.39 & 0.29 & 0.28 \\
\hline T10 & 0.27 & 0.29 & 0.25 & 0.28 & 0.30 & 0.16 & 0.24 & 0.08 & 0.28 & 0.28 \\
\hline T11 & 0.24 & 0.21 & 0.23 & 0.27 & 0.30 & 0.38 & 0.33 & 0.31 & 0.27 & 0.26 \\
\hline T12 & 0.29 & 0.29 & 0.23 & 0.28 & 0.30 & 0.29 & 0.22 & 0.23 & 0.28 & 0.28 \\
\hline T13 & 0.29 & 0.36 & 0.31 & 0.29 & 0.25 & 0.22 & 0.29 & 0.16 & 0.28 & 0.28 \\
\hline
\end{tabular}

TABLE III. WEIGHTED NORMALIZED SCORES FOR EACH ATTRIBUTE \& ALTERNATIVE

\begin{tabular}{|c|c|c|c|c|c|c|c|c|c|c|}
\hline Codes $\downarrow$ & $T L C$ & $T C U$ & $T L L$ & $T T D$ & $T S$ & $T N P$ & $T R R$ & $T C$ & $T D G$ & $T W G$ \\
\hline $\mathrm{W}_{\mathrm{j}} \rightarrow$ & 0.0807 & 0.0337 & 0.1282 & 0.1619 & 0.0809 & 0.0809 & 0.1619 & 0.0288 & 0.1823 & 0.0607 \\
\hline $\mathrm{T} 01$ & 0.022 & 0.007 & 0.020 & 0.043 & 0.021 & 0.028 & 0.053 & 0.011 & 0.050 & 0.016 \\
\hline $\mathrm{T} 02$ & 0.023 & 0.012 & 0.049 & 0.047 & 0.023 & 0.010 & 0.035 & 0.007 & 0.052 & 0.018 \\
\hline $\mathrm{T} 03$ & 0.023 & 0.010 & 0.039 & 0.047 & 0.023 & 0.021 & 0.041 & 0.011 & 0.051 & 0.017 \\
\hline $\mathrm{T} 04$ & 0.022 & 0.005 & 0.029 & 0.044 & 0.022 & 0.031 & 0.047 & 0.011 & 0.050 & 0.016 \\
\hline $\mathrm{T} 05$ & 0.023 & 0.007 & 0.033 & 0.045 & 0.023 & 0.028 & 0.053 & 0.007 & 0.050 & 0.017 \\
\hline $\mathrm{T} 06$ & 0.023 & 0.010 & 0.033 & 0.045 & 0.024 & 0.015 & 0.041 & 0.004 & 0.050 & 0.018 \\
\hline $\mathrm{T} 07$ & 0.021 & 0.010 & 0.039 & 0.045 & 0.023 & 0.015 & 0.038 & 0.004 & 0.051 & 0.017 \\
\hline $\mathrm{T} 08$ & 0.022 & 0.007 & 0.029 & 0.044 & 0.019 & 0.026 & 0.050 & 0.007 & 0.049 & 0.016 \\
\hline $\mathrm{T} 09$ & 0.023 & 0.012 & 0.049 & 0.045 & 0.022 & 0.018 & 0.044 & 0.011 & 0.052 & 0.017 \\
\hline $\mathrm{T} 10$ & 0.022 & 0.010 & 0.033 & 0.046 & 0.024 & 0.013 & 0.038 & 0.002 & 0.052 & 0.017 \\
\hline $\mathrm{T}_{11}$ & 0.019 & 0.007 & 0.029 & 0.044 & 0.024 & 0.031 & 0.053 & 0.009 & 0.048 & 0.016 \\
\hline $\mathrm{T}_{12}$ & 0.023 & 0.010 & 0.029 & 0.046 & 0.024 & 0.023 & 0.035 & 0.007 & 0.051 & 0.017 \\
\hline $\mathrm{T}_{13}$ & 0.023 & 0.012 & 0.039 & 0.047 & 0.021 & 0.018 & 0.047 & 0.004 & 0.051 & 0.017 \\
\hline $\mathrm{V}_{\mathrm{j}}^{*}$ & 0.023 & 0.012 & 0.049 & 0.047 & 0.024 & 0.010 & 0.035 & 0.002 & 0.052 & 0.018 \\
\hline $\mathrm{V}_{\mathrm{j}}^{\prime}$ & 0.019 & 0.005 & 0.020 & 0.043 & 0.019 & 0.031 & 0.053 & 0.011 & 0.048 & 0.016 \\
\hline
\end{tabular}

TABLE IV. SET OF WEIGHTS USED FOR SENSITIVITY ANALYSIS

\begin{tabular}{|l|c|c|c|c|c|c|c|c|c|c|}
\hline \multirow{2}{*}{$\begin{array}{c}\text { Weight } \\
\text { Used }\end{array}$} & \multicolumn{10}{|c|}{ Attribute } \\
\cline { 2 - 11 } & $T L C$ & $T C U$ & $T L L$ & $T T D$ & $T S$ & $T N P$ & $T R R$ & $T C$ & $T D G$ & $T W G$ \\
\hline AHP & 0.0807 & 0.0337 & 0.1282 & 0.1619 & 0.0809 & 0.0809 & 0.1619 & 0.0288 & 0.1823 & 0.0607 \\
\hline Equal & 0.1 & 0.1 & 0.1 & 0.1 & 0.1 & 0.1 & 0.1 & 0.1 & 0.1 & 0.1 \\
\hline Unequal & 0.05 & 0.05 & 0.05 & 0.05 & 0.1 & 0.05 & 0.1 & 0.01 & 0.5 & 0.04 \\
\hline
\end{tabular}

TABLE V. SEPARATION MEASURES AND RELATIVE CLOSENESS FOR EACH ALTERNATIVE TIRE FROM IDEAL SOLUTION AND RANK OF ALTERNATIVE TIRE

\begin{tabular}{|c|c|c|c|c|c|c|c|c|c|c|c|c|}
\hline \multirow{2}{*}{\begin{tabular}{|c|} 
\\
Tire \\
Codes
\end{tabular}} & \multicolumn{4}{|c|}{$\begin{array}{l}\text { if } \mathrm{AHP} \text { weights were } \\
\text { given to all attribute }\end{array}$} & \multicolumn{4}{|c|}{$\begin{array}{c}\text { if equal weights } \\
\text { were given to all } \\
\text { attribute } \\
\end{array}$} & \multicolumn{4}{|c|}{$\begin{array}{c}\text { if unequal random } \\
\text { weights were given to } \\
\text { attributes }\end{array}$} \\
\hline & $S_{i}^{*}$ & $S_{i}^{\prime}$ & $C_{i}^{*}$ & 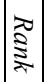 & $S_{i}^{*}$ & $S_{i}^{\prime}$ & $C_{i}^{*}$ & 胥 & $S_{i}^{*}$ & $S_{i}^{\prime}$ & $C_{i}^{*}$ & $\underset{\mathbb{Z}}{\mathbb{Z}}$ \\
\hline $\mathrm{T} 01$ & 0.041 & 0.005 & 0.108 & 13 & 0.049 & 0.009 & 0.153 & 13 & 0.022 & 0.006 & .105 & 13 \\
\hline T02 & 0.005 & 0.042 & \begin{tabular}{|l}
0.899 \\
\end{tabular} & 1 & 0.016 & .045 & 0.743 & 1 & 0.002 & 0.025 & 0.856 & 1 \\
\hline T03 & 0.018 & 0.027 & 0.596 & 6 & 0.036 & 0.027 & 0.429 & 8 & 0.010 & 0.017 & 0.561 & 5 \\
\hline T04 & 0.033 & 0.012 & 0.268 & 11 & 0.049 & 0.010 & 0.165 & 12 & 0.021 & 0.008 & 0.259 & 10 \\
\hline $\mathrm{T} 05$ & 0.031 & 0.015 & 0.330 & 9 & 0.03 & 1.02 & 0.376 & 9 & 0.020 & 0.00 & 0.339 & 9 \\
\hline T06 & 0.019 & 0.026 & 0.580 & 7 & 0.018 & 0.037 & 0.668 & 5 & 0.010 & 0.017 & 0.589 & 6 \\
\hline $\mathrm{T} 07$ & 0.013 & 0.031 & 0.709 & 2 & 0.015 & 0.038 & 0.716 & 3 & 0.008 & 0.019 & 0.711 & 4 \\
\hline T08 & 0.030 & 0.013 & 0.298 & 10 & 0.03 & 0.020 & 0.371 & 10 & 0.020 & 0.007 & 0.311 & 11 \\
\hline T09 & 0.015 & 0.035 & 0.696 & 3 & 0.033 & 0.036 & 0.521 & 6 & 0.008 & 0.021 & 0.653 & 3 \\
\hline $\mathrm{T} 10$ & 0.017 & 0.029 & 0.633 & 4 & 0.015 & 0.044 & 0.742 & 2 & 0.008 & 0.020 & 0.647 & 2 \\
\hline T11 & 0.035 & 0.011 & 0.244 & 12 & 0.042 & 0.014 & 0.252 & 11 & 0.023 & 0.008 & 0.245 & 12 \\
\hline $\mathrm{T} 12$ & 0.024 & 0.024 & 0.497 & 8 & 0.028 & 0.028 & 0.500 & 7 & 0.012 & 0.017 & 0.497 & 8 \\
\hline T13 & 0.018 & 0.027 & 0.604 & 5 & 0.017 & 0.039 & 0.701 & 4 & 0.011 & 0.018 & 0.611 & 7 \\
\hline
\end{tabular}

\section{DISCUSSION}

For an automobile project in Saudi Arabia, the goal set was to use a scientific multi criteria approach to make sure that the selected tire (among available alternatives) complies with prospective automobile performance. For the assessment of alternative automobile tires multiple criteria, such as tire sustainability, tire road performance, environmental issues, tire purchase cost and tire road grip are taken into account by the decision makers. The decision makers were interested not only in ranking alternatives but also in establishing the superiority of an alternative over others. There are varieties of attributes which may either support or oppose a particular alternative. By employing a single attribute analysis, as presented in Table III, it is evident that each given attribute produced significantly different preference choices. For example, if one chooses to maximize TCU (tire cushioning) of the automobile the first three preferences are tire T02, T09 and T13. Whereas to minimize tire noise pollution (TNP) the first three preferences are T02, T10 and T06. So it is observed that a multiple criteria analysis approach is more suitable than a single criterion analysis. When considering multiple criteria and attributes, the presented approach used ten attributes to assess alternative tires.

Similarly, using expert opinion and pairwise comparison of attributes, weighted normalized weights for each attributes obtained. Further considering multiple attributes, their corresponding weights and objective function; thirteen alternative tires evaluated. From Table $\mathrm{V}$ it is clear that alternative tire T02 is the first, and T01 is the last preferred choice, if AHP weights are assigned to each attributes. In case, 
persons involved in decision-making are of the opinion that equal or unequal random weights given to all tire attributes, it is evident that the present model exhibits sensitively. The sensitivity analysis shows variation in the ranking of alternative tires (Table V). After the sensitivity analysis, tire T02 with load carrying capacity of $1090 \mathrm{~kg}$, having very good tire cushioning while driving, having 2.5 years of life, the best thread depth, and very excellent tire grip in dry weather is the ideal first preference choice. In case, if the inclination towards an ideal preference is not satisfactory, then this approach is quite helpful to an analyst who is interested not only in ranking alternatives but also in establishing the superiority of an alternative over others.

\section{CONCLUSION}

The paper presents a multi criteria approach for practical decision-making. Here the approach evaluates the decision hierarchy and derives weights for multiple criteria and their attributes. The approach also incorporates these weights and does multi criteria decision analysis. The model synthesizes the preference relationships for each alternative tire to produce the desired outranking relationship between the entire alternatives. The evaluation criteria for alternative tires were broadly related to tire sustainability, tire road performance, environmental issues, and tire purchase cost and tire road grip. In the presented model, limiting factor is five criteria and ten attributes, to assess the thirteen tires. Considering the expected growth of automobile manufacturing sector, in future, one could extend the present work with other criteria and attributes, and also he/she incorporates the fuzzy characteristics. In the auto industry, the approach is quite helpful to any decision maker who is interested not only in ranking alternatives but also in establishing the superiority of an alternative over others if it exists.

\section{Acknowledgment}

Authors are thankful to the Research Center of College of Engineering, Deanship of Scientific Research, King Saud University for the support.

\section{REFERENCES}

[1] B. Rodgers, W. Waddell, "Tire Engineering Science and Technology of Rubber", Science and Technology of Rubber, Elsevier, 2005

[2] M. J. L. Boada, B. L. Boada, D. Garcia-Pozuelo, V. Diazet, "Neuralempirical tire model based on recursive lazy learning under combined longitudinal and lateral slip conditions", International Journal of Automotive Technology, Vol.12, No.6, pp.821-829, 2011

[3] R. S. Vieira, L. C. Nicolazzi, N. Roqueiro, "Four-wheel vehicle kinematic and geometric constraints for definition of tire slip angle", International Journal of Automotive Technology, Vol. 13, No. 4, pp. 553-562, 2012

[4] N. T. Ratrout, "Tire condition and drivers practice in maintaining tires in Saudi Arabia", Accident Analysis \& Prevention, Vol. 37,No. 1, pp. 201206, 2005

[5] N. T. Rarout, I. A. Mahmoud, "Adequacy of the tensile/elongation test as a quality control criterion for vehicle tires", Polymer Testing, Vol. 25, No. 5, pp. 588-596, 2006

[6] M. A. Boodihal, A. Chethan, R. Swamy, K. P. Biligiri, "Development of tire/road noise assessment methodology in India", Case Studies in Construction Materials, Vol. 1, pp. 115-124, 2014
[7] N. T. Ratrout, "Evaluation of Passenger Car Tire Failure in Saudi Arabia", Arabian Journal for Science and Engineering, Vol. 36, No. 5, pp. 749-760, 2011

[8] M. Velasquez, P. T. Hester, "An Analysis of Multi-Criteria Decision Making Methods", International Journal of Operations Research, Vol. 10, No. 2, pp. 56-66, 2013

[9] T. L. Saaty, Decision making with dependence and feedback the analytic network process, RWS Publications, Pittsburgh, 1996

[10] T. L. Saaty, The analytic hierarchy process. McGraw-Hill, New York, 1980

[11] P. Aragonés-Beltrán, F. Chaparro-González, J. P. Pascual PastorFerrando, A. Pla-Rubio, "An AHP (Analytic Hierarchy Process)/ANP (Analytic Network Process)-based multi-criteria decision approach for the selection of solar-thermal power plant investment projects", Energy, Vol. 66, pp. 222-238, 2014

[12] J. Oberschmidt, J. Geldermann, J. Ludwig, M. Schmehl. "Modified PROMETHEE approach for assessing energy technologies". International Journal of Energy Sector Management, Vol. 4, No. 2, pp. $183-212,2010$

[13] M. Beccali, M. Cellura, M. Mistretta, "Decision-making in energy planning. Application of the Electre method at regional level for the diffusion of renewable energy technology", Renewable Energy, Vol. 28, N o. 13, pp. 2063-2087, 2003

[14] C. L. Hwang, K. Yoon, Multiple Attribute Decision Making: Methods and Applications, New York: Springer-Verlag, 1981

[15] C. L. Hwang, Y. J. Lai, T. Y. Liu, "A new approach for multiple objective decision making", Computers and Operational Research, Vol. 20, pp. 889-899, 1993

[16] R. Narain, R. C. Yadav, J. Sarkis. "Investment justification of advanced manufacturing technology: a review", International Journal of Services and Operations Management, Vol. 3, No. 1, pp. 41-73, 2007

[17] P. Putrus, "Accounting for intangibles in integrated manufacturing-nonfinancial justification based on analytical hierarchy process", Information Strategy, Vol. 6, pp. 25-30, 1990

[18] A. K. Sharma, K. P. Pandey. "Matching tire size to weight speed and power available for maximizing pulling ability of agricultural tractors", Journal of Terramechanics, Vol. 38, pp. 89-97, 2001

[19] S. J. Kim, K. S. Kim, Y. S. Yoon. "Development of a tire model based on an analysis of tire strain obtained by an intelligent tire system", International Journal of Automotive Technology, Vol. 16, No. 5, pp. 865-875, 2015

[20] M. M. Da Silva, R. H. Cunha, A. C. Neto, "A simplified model for evaluating tire wear during conceptual design", International Journal of Automotive Technology, Vol. 13, No. 6, pp. 915-922, 2012 